\title{
Alotriofagia ou síndrome de pica
}

\author{
Dr. Fabiano de Abreu Agrela Rodrigues ${ }^{1}$ \\ deabreu.fabiano@gmail.com
}

$\mathrm{PhD}$, neurocientista, neuropsicólogo, psicanalista e biólogo

\section{RESUMO}

Define-se pica como a ingestão compulsiva de alimentos não nutritivos, em quantidades relevantes e rotineiramente. Neste artigo pretende-se dar a conhecer a síndrome de pica e as razões que estão por detrás deste distúrbio que pouco consenso gera na comunidade científica.

Palavras-chave: síndrome; pica; distúrbio alimentar

\footnotetext{
${ }^{1}$ Neurocientista, Neuropsicólogo, Psicólogo, Psicanalista, Jornalista e Filósofo.

Integrante da SPN - Sociedade Portuguesa de Neurociências - 814, da SBNEC - Sociedade Brasileira de Neurociências e Comportamento - 6028488 e da FENS - Federation of European Neuroscience Societies PT30079.
} 
Agrela Rodrigues...

\title{
Allotriophagia or pica syndrome
}

\begin{abstract}
Pica is defined as the compulsive ingestion of non-nutritional foods, in relevant amounts and routinely. This article aims to make known the pica syndrome and the reasons behind this disorder that generates little consensus in the scientific community.
\end{abstract}

Keywords: syndrome, pica, eating disorder

Artículo recibido: 02 enero 2022 Aceptado para publicación: 28 enero 2022 Correspondencia: deabreu.fabiano@gmail.com Conflictos de Interés: Ninguna que declarar 


\section{INTRODUÇÃO}

A doença de Pica é considerada como um comportamento inadequado caracterizado por um padrão de apetite e desejo por substâncias não-nutritivas. A pica normalmente não apresenta situações de risco de vida, mas por vezes pode criar complicações graves devido a este comportamento psicogênico de um indivíduo. A apresentação clínica da pica é altamente variável e pode ser associada a características específicas das condições médicas resultantes e das substâncias ingeridas. Um padrão de consumo estranho pode levar a várias alterações nos tecidos duros e moles da cavidade oral, o que pode levar ainda mais a ulcerações e dores pulpares.

\section{ESTUDO}

A palavra "Pica" deriva da palavra em latim para nomear o pássaro mais conhecido por pega, uma espécie de ave que se alimenta do que quer que encontre. "Pica" significa apetite pervertido por substâncias que não são adequadas como alimento sem valor nutricional, tais como tijolos, barro, terra, gelo entre outras. Durante séculos, associavase que as pessoas com desejo de alimentos invulgares podiam sofrer de distúrbios do sangue e da tez verde, que foi descrito pela primeira vez por Lange e nomeado como síndrome clorótico por Verandal em 1600.

Pica tem sido considerada um sintoma de anemia desde a época de Hipócrates. A resposta à questão de saber se a anemia por deficiência de ferro é uma causa ou um efeito da pica é ainda desconhecida. Esta síndrome é observada mais frequentemente durante o $2^{\circ}$ e $3^{\circ}$ anos de vida e é considerada inapropriada para o desenvolvimento em crianças com mais de 18-24 meses. A investigação sugere que a pica ocorre em 25\%-33\% das crianças pequenas e $20 \%$ das crianças atendidas em clínicas de saúde mental. Uma diminuição linear da pica ocorre com o aumento da idade. A pica estende-se ocasionalmente à adolescência, mas raramente é observada em adultos que não são deficientes mentais. Entre os indivíduos com deficiência intelectual, a pica ocorre mais frequentemente nos indivíduos com 10-20 anos de idade.

A exploração de objetos através da boca e da degustação faz parte do desenvolvimento normal, saudável e não é considerado um comportamento patológico associado à pica. Pica só é suspeita quando os objetos não alimentares são consumidos repetidamente ao longo de um mês ou mais, apesar dos esforços para reduzir o comportamento; o 
comportamento é considerado inadequado para a idade de desenvolvimento do indivíduo (isto é, para além dos 18 meses); não é uma prática cultural; e o comportamento é um sintoma de outra desordem mental e é suficientemente preocupante para justificar atenção médica. (STIEGLER 2005)

Os resultados físicos podem incluir manifestações de ingestão tóxica (por exemplo, envenenamento por algum componente toxico), manifestações de infeção ou infestação parasitária, manifestação gastrointestinal e manifestações dentárias. As manifestações gastrointestinais podem incluir problemas intestinais mecânicos, obstipação, ulcerações, perfurações e obstruções intestinais causadas pela formação de bezoar e a ingestão de materiais indigestíveis no trato gastrointestinal. Manifestações dentárias comuns são abrasão dentária grave, abfração e perda de dentes superficiais.

A mastigação de géneros abrasivos leva à escavação e ranhuramento das jantes de dentina e esmalte afiado, em contraste com o esmalte liso visto na erosão. Além disso, as facetas de desgaste não correspondem na posição intercuspal, como no atrito.

As teorias relativas aos efeitos nutricionais diretos da pica estão relacionadas com características de materiais específicos ingeridos que deslocam a ingestão alimentar normal ou interferem com a absorção de substâncias nutricionais necessárias. Os efeitos nutricionais que têm sido ligados a casos graves de pica são síndromes de deficiência de ferro e zinco; contudo, estes conceitos ainda não são claros.

Várias averiguações que podem ser realizadas são investigações de rotina do sangue para excluir deficiências nutricionais, para prevenir e verificar a existência de distúrbios gastrointestinais são o exame de bário gastrointestinal superior e inferior, o exame de imagem a intervalos regulares para rastrear alterações na localização de materiais ingeridos, endoscopia gastrointestinal superior para diagnosticar e identificar quaisquer lesões associadas.

A literatura científica disponível sobre pica contém relatórios de vários tratamentos para pica. Existem várias formas de tratar o problema incluindo abordagens nutricionais, psicológicas, farmacológicas, comportamentais, ecológicas e sensoriais.

Para construir um tratamento adequado é muito importante que o médico e o nutricionista identifiquem os hábitos alimentares da pessoa. É também recomendada a realização de exames para identificar as deficiências nutricionais e dessa forma o profissional de saúde 
consegue ajudar a orientar a pessoa para fazer uma alimentação mais adequada e, caso necessário, iniciar a suplementação de vitaminas e minerais.

Além disso, caso seja verificada que a pica está relacionada com prisão de ventre, anemia ou obstrução intestinal, o médico pode ainda indicar a realização de outros tratamentos mais direcionados. Em alguns casos, o acompanhamento com psicólogo ou psiquiatra pode também ser importante, pois ajuda a compreender que aquele automatismo não é apropriado, particularmente para pessoas que não têm qualquer tipo de deficiência nutricional que fundamente o comportamento.

As intervenções nutricionais funcionam obviamente com a introdução de suplementos nutricionais. Estes são frequentemente utilizados para reduzir a pica sendo que os suplementos à base de ferro são mais frequentemente recomendados, e as reduções de pica ocorrem em alguns casos. Outro complemente usado com bastante frequência é o zinco.

Por outro lado, muitas vezes uma intervenção psicológica é aconselhada. Aconselhamento e psicoterapia têm sido recomendados para indivíduos em quem se acredita que a pica é atribuível a perturbações emocionais ou psicogénicas. Intervenções farmacológicas são frequentemente utilizados para tratar pica sendo que os medicamentos que usam inibidores seletivos da recaptação de serotonina são mais frequentemente recomendados. Sendo que estes podem ser utilizados em esforço conjunto com correções comportamentais.

\section{CONCLUSÃO}

- A serotonina atua regulando o humor, sono, apetite, ritmo cardíaco, temperatura corporal, sensibilidade, funções cognitivas e é importante na transmissão de sinais entre o cérebro e sistema digestivo.

- Quando se encontra numa baixa concentração, pode causar mau humor, dificuldade para dormir, ansiedade ou mesmo depressão.

- Baixos níveis de serotonina aumentam compulsões alimentares. O declínio cognitivo relacionado ao sistema límbico acarreta numa menor orientação sobre o risco alimentar.

- Levando em consideração a relação da síndrome com a anemia e a serotonina, deve se levar em consideração a carência de nutrientes e/ou uma disfunção neste neurotransmissor. 
- Alimentos com complexo B são ótimos aliados no combate a anemia e na formação de serotonina.

- A pica é uma síndrome que é facilmente identificável, mas, o seu tratamento deve ser feito por um conjunto multidisciplinar de profissionais. Desta forma, médicos, nutricionistas e psicólogos devem unir esforços para encontrar um caminho para a cura que seja sustentado.

\section{REFERÊNCIAS BIBLIOGRAFICAS}

STIEGLER, L.N, (2005), Understanding Pica Behavior, Focus on Autism and Other Developmental Disabilities 20(1):27-38

DOI: $10.1177 / 10883576050200010301$

Feinstein, A. (2000, March 5). PICA. Message posted to St. John'sUniversity Autism and Developmental Disabilities List, archived http://maelstrom.stjohns.edu/archives/autism.html

Roberts-Harewood, M., \& Davies, S. C. (2001). Pica in sickle cell disease: "She ate the headboard." Archives of Disease in Childhood, 85 (6), 510

Rojahn, J., McGonigle, J. J., Curcio, C., \& Dixon, M. J. (1987). Suppression of pica by water mist and aromatic ammonia: A comparative analysis. Behavior Modification, 11(1), 65-74 